\title{
Focusing on People, Communities and Commerce: Interdisciplinary Research as a Multiple Lens
}

\author{
Susan Ciccotosto ${ }^{1}$,Josephine Pryce, \\ Taha Chaiechi, andJohn Hamilton
}

School of Business, James Cook University, Cairns Campus

Heron Loban

School of Law, James Cook University, Cairns Campus

\begin{abstract}
Universities, as knowledge intensive communities, seek to encourage multi-disciplinary research. Using a social capital framework, this paper explores the experiences of researchers from different disciplines within the Business and Law Schools at an Australian regional University. Social capital views organisations as a social community (community of practice) deriving distinctive advantage through speed and efficiency in creating, accessing, and transferring knowledge. Members of a multi-disciplinary research group combined complimentary viewpoints on the concept of 'value' to write a journal article on tension between different sections of society on an agreed topic. Undertaking a process of discussion, negotiation and debate to produce the article led to interesting ideas and viewpoints, new avenues of thought and "Eureka" moments, from which surfaced new ways of thinking about the problem. Using the reflections of the different team members, this paper shows how the information transfer across discipline boundaries and between quantitative and qualitative researchers can lead to a greater understanding of the complex web of societal life. This information transfer informs and enriches understandings of complex situations and assists the researchers to redefine problems outside of the normal boundaries of research.
\end{abstract}

I think of the story of the blind men and the elephant. This is a tale of six men, each of whom touched a different part of an elephant, unable to see what their hands were resting on. Asked to describe what they had touched, the man who felt the side of the elephant said, "I touched a wall," and the man who felt the elephant's tusk said, "I touched a spear." The six men argued among themselves--was it a snake, a cow, a piece of rope? Only when they worked together, sharing their different ideas and experiences, were they able to discover the truth (Member 2)

$\mathrm{U}$ niversities are becoming more focussed on interdisciplinary research. Increasing interest in this area is based on foundational beliefs that interdisciplinary research is more capable of finding solutions to complex problems and enables greater creativity. Emphasising academic commitment to these principles, a number of universities have made interdisciplinary research part of their strategic intent. There has also been an increase in calls

\footnotetext{
${ }^{1}$ Corresponding Author: School of Business, James Cook University, Cairns Campus, email susan.ciccotosto@jcu.edu.au, Ph 40421496
} 
for more interdisciplinary research from governments and industry. More grants are being offered with the expectation that interdisciplinary teams, both internal to a university and from a combination of universities, will be formed to carry out research in such topical areas as climate change and the environment (Haythornthwiate, 2006; Strober, 2011).

Bordons et al. (1999) notes that increased specialisation occurred as part of an increase in the body of knowledge in a discipline. Researchers must specialise in order to fully understand a chosen topic because the increasing volume of knowledge requires immersion in the details of the chosen area (Strober, 2011). However Carlisle (2004) argues that it is at the boundary between different specialisations where new ideas grow (see also Haythornthwaite, 2006). This process may not be as simple as one may think. Transferring knowledge between differing specialisations or disciplines, where there exists differing ontologies and epistemologies, can be difficult when there is little shared understanding (Strober, 2011). To foster interdisciplinary work requires researchers to overcome their individual preferences regarding research style and to embrace difference. Only when there is a willingness to overcome preferred ways of knowing and doing will there be successful knowledge transfer which will result in new knowledge (Haythornthwaite, 2006)

With the mounting importance of such research within the academic environment, this paper offers some insight into the initial development of an interdisciplinary team utilising the reflections of a small intra-campus team on a small regional Australian university campus. The paper begins with a discussion of the meaning of interdisciplinary research, followed by an explanation of social capital. The case study will then be introduced and discussed together with some impacts for the development of multidisciplinary research groups. The paper will end with some concluding remarks, including some suggestions for further research.

\section{Interdisciplinary Research}

A number of articles discuss what constitutes a 'discipline' and also 'interdisciplinary.' Strober (2011) considers this in some detail. Disciplines have been considered to exist when a university has a department, specifically named, or a major in a degree which encompasses the body of knowledge covered by the discipline. There is agreement that a discipline is a body of knowledge and that interdisciplinary teams require that knowledge be transferred between members of the team so that new knowledge can be created. Bordons (1999) considers interdisciplinarity to be defined as the collaboration between researchers from different fields.

Palmer and Neumann (2002) note that at an individual level many researchers read widely, moving beyond what may be considered to be specific to their own discipline. These individuals show an interest in the boundaries of their own discipline, such as researchers in accounting who consider social theories to explain the production of accounting numbers, or researchers in tourism who consider psychological motivation to tourist behaviour.

Researchers who explore beyond their discipline build networks to enable knowledge transfer to overcome a lack of knowledge. These networks occur both within the researchers' specific discipline and within the area of interest. It could be argued that such exploration is inefficient, taking a great deal of time for an individual researcher to become reasonably knowledgeable in this new area. So, specific interdisciplinary teams should come together to enable knowledge transfer in a more efficient and effective manner. 
Haythornthwaite (2006) examines the social structures of three different networks built to engage in interdisciplinary research, utilising a social and knowledge transfer viewpoint of the teamwork. She argues that interdisciplinarity requires knowledge transfer and individuals within a team should know where to access specific information within the team. This would lead to greater connections between individuals to enable knowledge transfer. Her research also showed the kinds of learning that are important in such teams in which domain specific knowledge quickly gives way to knowledge about process, method, technology and gaining network benefits while engaging in joint research,. These knowledge transfers highlight important aspects of interdisciplinary research activity and the kinds of exchanges that need to be acknowledged as real parts of the work and practices of such teams.

Rhoten (2005) is more critical of the structures put in place to encourage multidisciplinary research, finding that there may be little actual multidisciplinary research taking place. While there are numerous multidisciplinary centres, individuals within do not cooperate but rather continue to study their topic in their own way, according to the norms and values of their own discipline. " $[\mathrm{M}]$ ost interdisciplinary research centres have a tendency to become a nexus of loosely connected individuals searching for intersections, as opposed to cohesive groups tackling well-defined problems.” (Rhoten, 2005, p 9). Members of these centres who were 'assigned' to their roles are often dissatisfied with the reward systems in place and feel their time spent in the centre is wasted. Rhoten concludes by recommending that multidisciplinary research be built around specific problems or projects and be composed of networks of practice, where information flows may not necessarily produce outputs in the short term.

This research considers a discipline to be a body of knowledge that is signified by a major in a degree. Haythornthwaite's (2006) research argues that effective knowledge transfer is required when interdisciplinary work occurs between the members of a team and concentrates on how this occurred. In line with this rationale, an interdisciplinary team is one in which knowledge transfer takes place to enable research outcomes that may differ from those of a single discipline. To enable interdisciplinary research, knowledge transfer which overcomes different ontologies and epistemologies requires an openness to change (Strober, 2011). Such openness is built upon trust between individuals.

From this literature, interdisciplinary teams are networks of individuals, each with an understanding of a different body of knowledge. The team should preferably undertake research on a specific topic of interest to members of the network. These teams need to be able to communicate knowledge of the topic between different members of the network and, at the same time, receive and benefit from the knowledge of others in the network. Communication is more likely to take place when trust has built up overtime. This implies a long term relationship between members of the team. These relationships can be viewed as examples of individual and organisational social capital. Universities should be able to leverage their social capital. An explanation of social capital follows.

\section{The Social Capital Frontier}

Social capital facilitates a network's capacity and capabilities for creating, sharing and accessing knowledge (Nahapiet and Ghoshal, 1998). Organisations are social communities (communities of practice) which derive distinctive advantage by using social networks to quickly and efficiently access and transfer knowledge that exists within the community, using it to create new knowledge. Grounded in this notion of social capital is the focus on the 
importance of relationships and ties that form the basis for social interaction (Bourdieu, 1986; Baker, 1990; Nahapiet and Ghoshal, 1998). The crux of social capital theory is that it is these network ties and relationships which provide valuable resources to members in an efficient and cost effective manner, leading to benefits in forms of access, timing and referrals of information (Burt, 1992). Social capital highlights the importance of strong personal relationships developed over a period of time. These personal relationships form the basis for goodwill, trust, cooperation and collective action in organisations. They allow people to contribute to the community of practice with an expectation that they too will benefit in some form in the future through knowledge diffusion and transfer (Wenger, et al. 2002).

Intellectual capital has to do with knowledge and knowing capability of a social collectivity, for example an organization, a community or a professional association such as accountancy, law, medicine and so on (Nahapiet and Ghoshal, 1998; Coleman, 1988). It therefore represents an invaluable resource for human action arising from integration, sharing and access, leading to knowledge creation. Intellectual capital exists in the form of explicit and tacit knowledge, created through the combination and exchange of existing intellectual resources within networks (Nahapiet and Ghoshal, 1998). It is argued that knowledge is held by different parties, hence it is essential to combine and exchange this knowledge through social interaction in a collaborative and team environment. Combination involves incremental change and development from existing knowledge and experiences of different parties, and exchange has to do with the transfer and diffusion of explicit and tacit knowledge through social interaction (Nahapiet and Ghoshal, 1998).

Multidisciplinary collaborations must manage interpersonal relationships within a team. Researchers from different disciplines have usually trained in different departments, have had different advisors, publish in different journals, and attend different conferences. Their social bonds may be comparatively weak (Granovetter, 1973), increasing the difficulty for effective knowledge transfer (Cummings and Kiesler, 2005). The social capital of the university can be utilised to overcome weak social bonds, developing trust and effective interdependence which it is argued will lead to more effective knowledge transfer. The next section will examine the formation of an interdisciplinary group on a small regional campus. The group used social ties formed over several years. Mutual trust and respect between individuals within the group had developed over time. Utilising these previously built social ties, each team member worked to benefit other team members with the expectation of similar support at some future, yet undetermined, time.

\section{Genesis of the Multidisciplinary Team}

Although there is increased interest in interdisciplinary research within this university's environment, the team came together as an initiative to encourage its members to increase individual research outputs and to enhance promotion opportunities as well as to provide an interesting forum for new areas of research.

Over the past three years, a group of four academic staff would meet for social occasions, and share a coffee or lunch. The group included an indigenous lecturer in law, a lecturer in Management and Human Resources, a lecturer in Economics and a lecturer in Accounting. The discussion would turn to research and the group decided that it would be helpful, motivating and interesting if they could envisage a way to undertake a research project together by forming an interdisciplinary team. During this period the team was joined by a 
lecturer in Management. The team began by applying (unsuccessfully) for grants. Without funds, the question became what project could the team undertake that would provide impetus, but required little or no expense.

The team considered a specific case study to be an essential component to focus the team's efforts. Two members of the team had debated for some time on a case study, which the team considered represented a research opportunity, regardless of the success or otherwise of grant applications. A brief outline of this case study follows.

\section{A Serendipitous Nexus: The Torres Strait Fishing Zone}

Both voluntary agreements and a fish management scheme exist in the Torres Strait in an endeavour to limit the fishing effort and provide for equitable shares for fishers, however there is continuing tension between the inherited rights of indigenous fishers and the, possibly, third or fourth generation commercial fishers (English, 2001). Indigenous people living on the islands of the Torres Strait place great importance on their traditional way of life and livelihood, which includes traditional fishing (English, 2001). Commercial fishers also have a connection with fishing as an activity and a way of life which transcends the 'commercial,' with the concept of profit as its chief aim. Threats to commercial fishers' livelihoods may affect not only their financial affairs, but also their physical and emotional health. Closing off valuable fishing areas to commercial fishers not only impacts upon the fishers themselves, but also on the families and fishing centred businesses in coastal and regional areas (Shaw, 2008).

The case of $R v$ Nona and Gesa brought to the fore the issues of fishing rights in the Torres Strait, though not in the context of native title or sea rights as one might expect, but rather in a criminal case involving the prosecution of two Torres Strait Islander (TSI) men in the District Court of Queensland. This case brought sharply into focus the nature and depth of the conflict between TSI fishers and non-indigenous commercial fishers fishing in the waters of the Torres Strait. On 6 May, 1998, the dinghy of a commercial mother ship was fishing in the waters outside of Mer (Murray Island) in the eastern part of the Torres Strait. Whilst there, the commercial fishers in the dinghy were met by Nona and Gesa and another Torres Strait islander from Mer in another dinghy. Nona and Gesa contended that the commercial fishers were within an exclusive economic zone which was the subject of a 'gentleman's agreement ${ }^{\text {ii }}$ between the Torres Strait Islander people of that area and commercial fishers and that by being within that zone the commercial fishers were in breach of that gentleman's agreement. The TSI took from the commercial fishers a quantity of fish and some cigarettes. The TSI were charged with armed robbery (they were holding fishing spears) and were found not guilty.

After the case, indigenous people demanded that all non-indigenous fishers (i.e. commercial fishers) leave the area by the $31^{\text {st }}$ March, 2001. There were threats of violence and talk of 'war.' A number of commercial fishers banded together and called the indigenous fishers' bluff with tensions continuing until a phone call between the protagonists ended the standoff (English, 2001). This case highlights the conflict between indigenous people who see the fishing of their traditional waters as a native right and the commercial fishers who also view fishing as part of their identity and tradition, exhibiting an emotional and existential attachment to their job (English, 2001, Shaw, 2008). 
This case was considered appropriate because members of the team had access (network connections) to the indigenous fishers, the commercial fishers and a member of the legal profession who has represented both sides at different times. The team decided to support our indigenous Law colleague to write a paper on the case study taking a multidisciplinary viewpoint. The Law colleague undertook the major writing of the paper, with contributions from other members of the team, which discussed the difficulty of using the law in cases where there were competing views and cultural complexities.

\section{Reflections on a team}

Social capital represents the ties between members of a network, built over a period of time. Members of the team had known each other for various periods, from one to several years. The ties are built as people make connections with each other. These connections are not necessarily built in a strictly business environment, but can also be built on a purely social level. In this team's case, they were blended. Social engagements were also times to explore our roles as researchers. One member commented that "over the years we developed a pattern of just knocking on each other's door to share ideas or thoughts" (Member 2). Another discussed how meeting for coffee produced conversations about possible research topics (Member 4). It was at one of those social occasions (lunch in fact) where the possibility of forming an interdisciplinary research group was suggested. One team member felt that "[i]t was a natural extension of the get-togethers we were having” (Member 2). For another team member it was to "put some quick runs on the board" (Member 1), producing research output quickly and with less effort. Momentum was an aspect mentioned by another member of the group:

If we had a group in place, when one or two members were busier, the others would be able to carry the load and keep the impetus going. Eventually the roles would change and other members would be able to take a greater role. The impetus was the thing, once we were moving it should roll on (Member 4)

Since research is not the only work-related activity undertaken by academics, the tension between good teaching and good research remains. At times teaching requires a greater commitment and research can suffer. The comment above shows some of this tension, but also indicates trust shown to other members of the team. These 'others' are trusted to remain committed in times when this individual is unable to spend as much time researching. There is also trust that when this person is carrying a greater research load, others will reciprocate at a later date.

Trust is one of the basic requirements for social capital to exist. Although no other member of the team mentioned trust when discussing team formation, it came very much to the fore when the team decided to consider a paper on the $R v$ Nona and Gesa case. The original concept was to assist the Law colleague to write a journal article on this topic. The team committed to assisting the colleague, who promised to write an article. It was anticipated that each member of the group would put together a short comment of approximately five hundred words that situated the case study within their discipline. The Law colleague was allowed to choose any or all of any comment, depending on how the various points of view fitted into the overarching argument of the article. Most members of the team admitted to being at a complete loss at the beginning of the process. The Accounting colleague was "not sure how 'accounting' would fit into a law case like this, I didn't think it was particularly 
relevant." Another read the developing article when the Law colleague "sen[t] around the work she had done on the paper on fishing, I did not think that I could contribute to it" (Member 2). Of the team, two members were working on the paper in more detail, the Law colleague and another member with previous business experience in the fishing industry. The team decided to meet to discuss the paper so that members who were struggling could gain a greater understanding on the basics of the topic.

This meeting made a difference - moving those who were unsure of their role into a clearer vision of the topic and the paper we were writing. Clearly this was beneficial, however the meeting made a greater impact:

It wasn't till we had a get-together over coffee that I had an epiphany and realised that I could add an interesting outlook to the paper (Member 2)

Team members, discussing the project face to face, found a common theme which ran through the project that resonated with each member, on different levels and bringing to bear different bodies of knowledge. Carlisle (2004) mentions knowledge transfers at the boundary, and the team had found a concept that became a bridge between the disciplines. Within this project, that was the concept of 'value.' Value is a differing concept under the law, in business, in economics and between social systems. The members saw, not only the original paper, but also how this project could be connected with their own disciplines:

Critical accounting has long discussed the notion of value and how that can be measured. There have been different normative ideas of what constitutes value, and how the value of a firm can be calculated. I suddenly realised that this was where this research project sat in the accounting literature, in the notion of value and the tension between profit measurement and the value placed on the resource by the indigenous people (The accounting colleague)

Face to face discussion had brought about clarification to the group. One member explained "the process of brain storming amongst members is helpful in enlightening research barriers and key objectives" (Member 3). This confirmed the comments from one member of the team who had been involved in research teams previously - "extended discussion or debate - one of the key benefits of working in a team" (Member 1). In their reflections of the process to date, all members of the team emphasised the importance of conversation. Another added bonus of conversation included valued feedback from members when discussing possible topics of research: as a member called it, "a 'sounding-board' for research ideas" (Member 5). Members valued conversations and found, as Member 5 continued, "discussions/research targeting to be stimulating and insightful."

There was agreement that the team, even in these early stages (the team has only existed for one year), has increased and strengthened ties that already existed between members. One member stated "[f]rom these enthusiastic early days a strong friendship emerged" (Member 5). Another member noted an increase in "members' sense of affiliation and partnership" (Member 3). However, this should not be taken to indicate that there has been no conflict within the team from time to time. Robust discussion has taken place between members who have differing ontologies and epistemologies. Team members have maintained a willingness to accept difference as part of interdisciplinary research. One member reflects that "[t]rust and mutual confidence are a key aspect of our synergies” (Member 2). As the team begins to 
produce journal articles and grant applications, the benefits to team membership are becoming clearer.

There is one cautionary note from a team member. Engagement in team activities "requires both time and resources that members take away from developing deeper expertise within their own disciplines” (Member 3). Time and energy are required from all members for the team to be successful and this, as one team member does go on to say, "results in enhanced learning from each other by communicating different methods, approaches, and findings" (Member 3).

The purpose of building an interdisciplinary team is to create new knowledge and recognition through the dissemination of "quality research outputs that 'make-a-difference"'(Member 5). Members of the team are looking forward to further opportunities; as Member 5 comments: "This sharing of ideas is expanding the team's research capabilities and ideas base, and it is advancing both our collegiality and our productivity" and "[w]orking in this crossdisciplinary framework also triggers new approaches/ opportunities/ considerations when approaching research.” There is one last comment from a member that sums up how members feel about the future: "The PCC as a group and as an aspiring research hub has been strengthened in many ways and for me, I am no longer lost” (Member 1). The team is growing together.

\section{Discussion and Conclusion}

It is acknowledged that there are numerous interdisciplinary programmes, centres and teams already in existence; this team is but one. The authors do not contend that this interdisciplinary team represents all or any other interdisciplinary team, successful or otherwise. Generalisation is not possible from this study; however, the development of this team over the past year may present a possible model that highlights opportunities to develop similar teams in other university settings.

Leveraging social capital works. Already connected by strong social ties, the team members were able to cooperate together for the benefit of each other. Trust was central to this cooperation. Team members were willing to invest resources consisting of time and knowledge to benefit other members of the team. They expected other to reciprocate at some future time. Mutual trust enabled members to listen to others, who had different world views and ways of undertaking research, and accept those differences. There was evidence that this trust enabled social capital to increase between members over time.

Robust and open academic discussion improved knowledge transfer. Face to face discussion was found to be vital when team members wished to understand how different disciplines viewed the case. Face to face communication not only developed an understanding of other's viewpoints, but also opened team members to engage with their own knowledge base and bring that knowledge to bear on the problem. Team members found that it is through this discussion that they were able to understand the boundary between their research and others, and how those boundaries could be integrated. This is how new knowledge was developed. Academic debate also enabled each team member to look with a new lens upon their individual body of knowledge. From the case of the fishermen, the concept of 'value' became more problematic. Different disciplines with different viewpoints have made the team members more aware of how their own assumptions may have influenced their conclusions. 
All disciplines, collapsed into one concept, moving outward again to reconsider how real things really are.

As the team moves towards a greater understanding of each case study, each phenomenon that we use as an aid to knowledge transfer, the team anticipates that there will be a number of journal articles that will be produced. This is one of the purposes of academic research, for both individual and organisational benefits. Some of these journal articles will be discipline based, stretching the bounds of individual disciplinary knowledge, others can combine multidisciplinary concepts and discussions. However there appears to be a dearth of multidisciplinary journals in which these articles can be published. If there is a serious movement within the academic community towards interdisciplinary cooperation and the examination of phenomena from differing viewpoints, using differing ontological and epistemological perspectives, then it can be argued that the ability to publish multidisciplinary papers in appropriately peer-reviewed papers is an imperative. Publications are required for academic promotion. Interdisciplinary journals would not only encourage cooperation between disciplines, but signal to the academic community the importance placed upon such research and the production of such knowledge.

\section{WORKS CITED}

Baker, W. (1990).Market networks and corporate behaviour. American Journal of Sociology 96 : 589-625. Web: 18 July, 2010.

Bordons, M., M. A. Zulueta, F. Romero, and S Barrigon. (1999).Measuring Interdisciplinary Collaboration within a University: The effects of the multidisciplinary research programme. Scientometrics 46.3 : 383-398. Web: 14 December, 2011.

Bourdieu, P. (1986). The forms of capita In J G Richardson (Ed.), Handbook of theory and research for the sociology of education. New York: Greenwood, 241-258. Web. $16^{\text {th }}$ March, 2010.

Burt, R. S. (1992). Structural holes: the social structure of competition. Cambridge: Harvard University Press. Eprint. $6^{\text {th }}$ January, 2012.

Carlisle, P. R. (2004). Transferring, Translating, and Transforming: An integrative framework for managing knowledge across boundaries. Organization Science 15.5 : 555-568. Web: 14 December, 2011.

Coleman, J. S. (1988). Social capital in the creation of human capital. American Journal of Sociology, 94 : 95-120. Web: 18 July, 2010.

Cummings, J. N. and S Kiesler. (2005). Collaborative Research across Disciplinary and Organizational Boundaries Social Studies of Science. Scientific Collaboration 35.5 : 703-722. Web: 14 December, 2011. 
English, A. E. (2001). Snatching the Catch or Asserting Native Title Ownership? Native Title, Queensland's Criminal Law and Commercial Fishing. Native Title News, 5.6 ; 99-104. Web: 23 July, 2011.

Granovetter, M. S. (1973). The Strength of Weak Ties. American Journal of Sociology. 78.6 ; 1360-1380. Web: 7 August, 2008.

Haythornthwaite, C. (2006). Learning and Knowledge Networks in Interdisciplinary Collaborations. Journal of the American Society for Information Science and Technology 57(8) : 1079-1092. Web: 12 December, 2011.

Nahapiet, J., and S. Ghoshal. (1998). Social Capital, Intellectual Capital and the Organizational Advantage. Academy of Management Review 23.2 : 242-266. Web: 20 July, 2010.

Palmer, C. L. and L. J. Neumann. (2002). The Information Work of Interdisciplinary Humanities Scholars: Exploration and translation. The Library Quarterly, 72.1 : 85117. Web: 12 December, 2011.

R v Nona and Gesa, District Court of Queensland, Cairns, 29 January, 2001. Unreported. Web. $18^{\text {th }}$ July 2011.

Rhoten D. (2005). Interdisciplinary Research: trend or transition. Items Issues, 5 : 6-11. Web: 12 December, 2011.

Shaw, S. (2008). The Soul of the Fisher. Paper presented at The Annual Conference of The Australian Sociological Association, 2-5 December, Melbourne, Victoria. Web: 27 July, 2011.

Strober, M. H. (2011). Interdisciplinary Conversations: Challenging Habits of Thought. Stanford: Stanford University Press. Eprint. 6 ${ }^{\text {th }}$ January, 2012.

Wenger, E., McDermott R., Snyder W. M. (2002). Cultivating Communities of Practice: a guide to managing knowledge. Boston: Harvard Business School Press. Eprint. $7^{\text {th }}$ January, 2012. 